\title{
Conscientização do Cirurgião Dentista sobre a importância do pré-natal
}

\section{odontológico}

\author{
Dentist Surgeon awareness about the importance of dental prenatal
}

Recebido: 20/10/2021 | Revisado: 25/10/2021 | Aceito: 28/10/2021 | Publicado: 31/10/2021

\author{
Brenda Flores Rodrigues da Silva \\ Universidade Brasil, Brasil \\ E-mail: brendaflores1602@gmail.com \\ Amália de Almeida Pimenta Caetano \\ Universidade Brasil, Brasil \\ E-mail: amaliap.caetano@outlook.com \\ Thais Cordeschi \\ Universidade Brasil, Brasil \\ E-mail: thaiscordeschi@gmail.com \\ Denis Honorato Costa \\ Universidade Brasil, Brasil \\ Faculdade Santa Marcelina, Brasil \\ E-mail: hto@hotmail.com
}

\begin{abstract}
Resumo
Introdução: O pré-natal odontológico (PO) é um assunto pouco discutido com a população e se apresenta de forma controversa tanto para a gestante quanto para o cirurgião-dentista $(\mathrm{CD})$, mesmo estas pacientes fazendo parte de um grupo de risco devido as condições adversas geradas em razão de mudanças físicas, hormonais e psicológicas. Objetivo: Conscientizar o CD sobre a importância do pré-natal odontológico. Orientá-lo a incentivar as pacientes gestantes realizarem pré-natal odontológico. Assim como promover educação continuada para realizações de procedimentos prevenindo complicações durante e após a gravidez. Metodologia: Este estudo constitui-se de uma revisão de literatura, realizado entre março e setembro de 2021. A busca foi realizada na plataforma PubMed, a partir da fonte Medline, utilizando dados associados de atribuição de artigos, baseado nos últimos 10, com busca de textos completos de artigos em inglês e português dos tipos: Meta análise e Revisão Sistemática, em espécie humana apenas. A busca foi realizada baseada nas palavras-chaves: Assistência odontológica; gestantes; pré-natal odontológico; conscientização; conscientização pré-natal. Inicialmente foram listados 3.396 artigos, onde 19 destes foram escolhidos aleatoriamente, mas que estivessem diretamente ligados ao tema deste trabalho. Considerações Finais: Atualmente o conhecimento científico demonstra que o PO deve ser realizado pelos $\mathrm{CD}$, pois os possíveis fatores de risco podem determinar doenças mais graves durante o período gestacional.
\end{abstract}

Palavras-chave: Assistência odontológica; Gestantes; Pré-natal odontológico; Conscientização; Conscientização prénatal.

\begin{abstract}
Introduction: Dental prenatal care (OP) is a subject little discussed with the population and is controversial for both the pregnant woman and the dentist (DC), even these patients being part of a risk group due to adverse conditions generated due to physical, hormonal and psychological changes. Objective: To make the $\mathrm{CD}$ aware of the importance of dental prenatal care. Guide him to encourage pregnant patients to perform dental prenatal care. As well as promoting continuing education for performing procedures to prevent complications during and after pregnancy. Methodology: This study consists of a literature review, carried out between March and September 2021. The search was performed on the PubMed platform, from the Medline source, using associated data of article attribution, based on the last 10, with search of full texts of articles in English and Portuguese of the types: Meta analysis and Systematic Review, in human species only. The search was performed based on the keywords: Dental care; pregnant women; dental prenatal care; awareness; prenatal awareness. Initially, 3,396 articles were listed, of which 19 were chosen randomly, but that were directly linked to the theme of this work. Final Considerations: Currently, scientific knowledge demonstrates that the PO should be performed by DCs, as possible risk factors can determine more serious diseases during the gestational period.
\end{abstract}

Keywords: Dental care; Pregnant women; Dental prenatal care; Awareness; Prenatal awareness. 


\section{Introdução}

Pré-natal odontológico (PO), é a assistência prestada a gestante, visando orientar sobre os cuidados com a própria saúde e tratamento das possíveis doenças bucais já estabelecidas. Incluindo ações como a de desmitificação de crenças e preocupações sobre a gravidez e o tratamento dentário, buscando evitar complicações para a mãe e para o bebê durante a gestação e futuramente. (SIQUEIRA; COSTA \& ALMEIDA, 2020).

Uma grande parcela da população não tem de forma acessível informações sobre as alterações bucais e, principalmente, sobre as características do período gestacional (PG). Nessa fase, a gestante sofre importantes alterações tanto fisiológicas quanto emocionais, levando a paciente a recear o tratamento odontológico (OLIVEIRA et al., 2014).

A relutância das pacientes ao PO é um fato considerável. As gestantes são inseguras e presumem que o tratamento odontológico possa causar anormalidades congênitas, aborto ou influenciar de forma negativa o curso da gestação e, possivelmente, causar danos à mãe e ao bebê, quando na verdade a falta desses cuidados pode gerar tais preocupações (OLIVEIRA et al., 2014).

A conservação da saúde bucal durante o PG é essencial para que agravos dos fatores de risco não determinem doenças para a mãe e para o bebê, gerados pela falta de cuidado e falta de visitas ao cirurgião-dentista (CD) (SBP, 2020).

O objetivo geral deste estudo é conscientizar o profissional CD sobre a importância do pré-natal odontológico. Orientálo a incentivar as pacientes gestantes realizarem pré-natal. Assim como promover educação continuada para realizações de procedimentos prevenindo complicações durante e após a gravidez, como objetivos específicos.

\section{Metodologia}

Este estudo constitui-se de uma revisão de literatura, realizado entre março e setembro de 2021. A busca foi realizada na plataforma PubMEd, a partir da fonte Medline, utilizando dados associados de atribuição de artigos, baseado nos últimos 10, com busca de textos completos de artigos em inglês e português dos tipos: Meta análise e Revisão Sistemática, em espécie Humana apenas, A busca foi realizada baseada nas palavras-chaves: Assistência odontológica; gestantes; pré-natal odontológico; conscientização; conscientização pré-natal. Inicialmente foram listados 3.396 artigos, onde 19 destes foram escolhidos aleatoriamente, mas que estivessem diretamente ligados ao tema deste trabalho.

\section{Revisão de Literatura}

Durante o PG, ocorrem alterações físicas e psicológicas, mudanças estas relacionadas ao aumento excessivo dos hormônios (estrogênio, prolactina, progesterona, entre outros), capazes de comprometer e agravar reações inflamatórias no tecido gengival, intensificando o acúmulo de biofilme e bactérias nos dentes (ALEIXO, et al., 2016). O PG causa múltiplas mudanças no corpo das gestantes em prol do desenvolvimento do feto, parto e amamentação. Essas alterações geram também modificações na cavidade oral, que, em virtude de alterações hormonais, dieta, falta de conhecimento sobre a higienização, causam doenças bucais como gengivite gravídica (GG), cárie dentária, erosão dentária, xerostomia, periodontite e tumor gravídico, que se não observadas podem gerar complicações para a gestante e, consequentemente, para o feto. Nesse sentido, a conscientização sobre o PO deve ser enfatizada, assim prevenindo complicações locais e gerais durante a gestação e/ou puerpério e à saúde do bebê (LONDRINA, 2017, p. 263).

\section{Gengivite gravídica}

A gengivite gravídica (GG) pode ser considerada a doença bacteriana mais comum durante o PG (ZEMOLIN et al. 2017). Geralmente, ela começa entre o segundo e terceiro trimestre, sendo caracterizada por uma resposta agravada perante uma 
quantidade mínima de placa bacteriana devido às alterações hormonais. Clinicamente apresenta uma coloração avermelhada, edemaciada, sangramento ao toque ou escovação e fluxo do fluído do sulco gengival elevado (Figura 1). Os cuidados são baseados em limpeza diária dos dentes com uso de escova e fio dental e profilaxia profissional mensal ou trimestral, dependendo da necessidade de cada paciente (OLIVEIRA et al., 2014).

Figura 1 - Gengivite gravídica induzida por placa bacteriana.

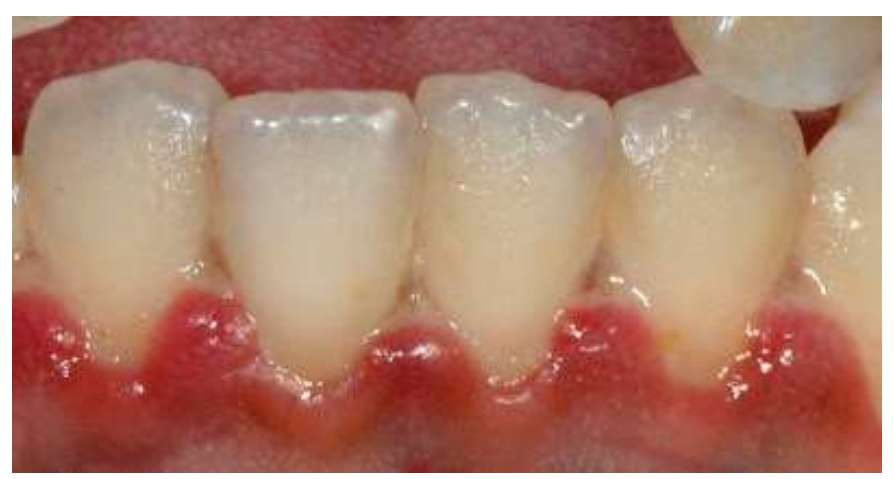

Fonte: < https://jornal.usp.br/universidade/estudo-testa-eficacia-de-produtos-no-tratamento-de-doencas-gengivais/>.

\section{Periodontite}

A periodontite (Figura 2) pode ser considerada um agravamento da GG, já que quando esta inflamação não é controlada pode ocasionar infecção, causando a perda do osso suporte, o periodonto (THAKUR et al., 2020).

Casos de agravamento ou de periodontite pré-instalada podem resultar em recessão gengival e mobilidade dentária, achados clínicos frequentes da doença referida (LONDRINA, 2017, p. 264).

$\mathrm{O}$ parto prematuro e o baixo peso do neonato têm sido relacionados à presença da doença periodontal na gestante. Segundo Amélia Mamede (2018), inflamações e infecções que podem acarretar alterações hormonais, neste sentido o organismo, para proteger o bebê, induz o nascimento prematuro, que por consequência o recém-nascido terá baixo peso. Entretanto, alguns estudos não obtiveram resultados consideráveis para afirmar a relação entre a doença periodontal e o parto prematuro e baixo peso do recém-nascido, logo, não ficando evidente tal correlação (SILVA et al., 2018).

Contudo, ainda que os estudos estejam em curso e apresentem opiniões divergentes, o tratamento periodontal, baseado em orientação/aprimoramento da higiene bucal, raspagem e alisamento radicular e profilaxia profissional é seguro para a gestante e para o feto, melhorando a qualidade de vida de ambos (EBRAHIM et al., 2014).

Figura 2 - Periodontite avançada.

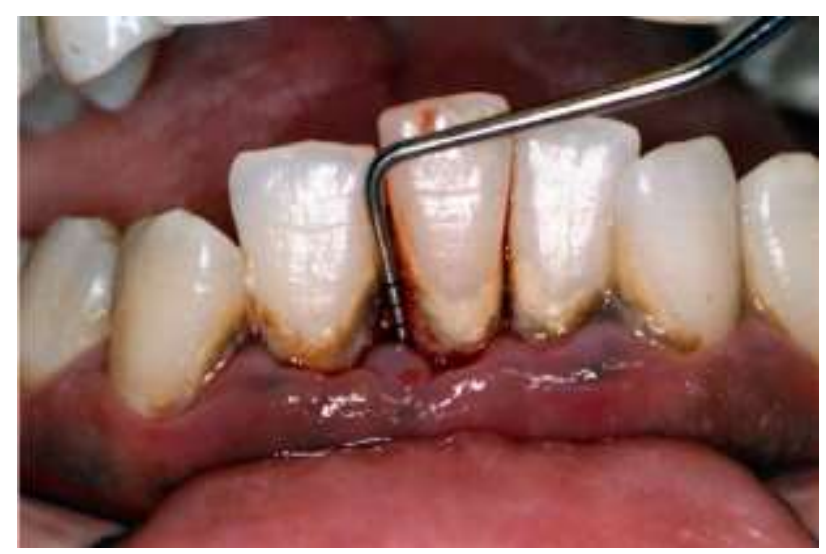

Fonte: < http://repositorio.unicamp.br/jspui/handle/REPOSIP/290423> 


\section{Cárie dentária}

A cárie dentária é uma disbiose caracterizada pela existência de variadas espécies microbianas (SILVA, 2020) causada pela presença de açúcar e pela interação dinâmica entre o dente e bactérias orais, associados ao potencial hidrogeniônico (pH) ácido em decorrência de uma dieta cariogênica. A lesão de cárie está diretamente relacionada com mudanças de hábitos de dieta e higiene bucal, que são mais comuns durante a gestação, e ainda, além das variações hormonais, nesse período há uma maior ocorrência de vômitos. Todos esses fatores podem modificar a flora oral, deixando os dentes mais predispostos ao surgimento da lesão de cárie (SBP, 2020, p. 7). Os cuidados preconizados se baseiam na interação entre o CD e paciente para aconselhar hábitos de higiene oral, monitoramento do estado da cavidade bucal, realização de profilaxia profissional e uso de flúor (LONDRINA, 2017, p. 264).

Figura 3 - Lesão de cárie oclusal.

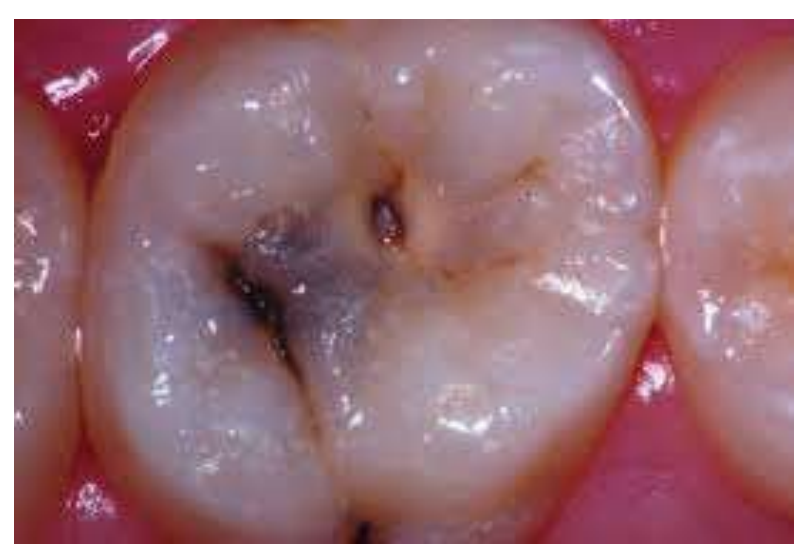

Fonte: 〈https://statics-submarino.b2w.io/sherlock/books/firstChapter/28283384.pdf>

\section{Erosão dentária}

A erosão ácida intrínseca corresponde à perda de minerais dos dentes sem a presença de bactérias e por fatores que se originam no interior do organismo. (MANGUEIRA et. al, 2011). Pode ocorrer durante a gestação em decorrência dos vômitos frequentes, podendo causar sensibilidade ao calor e ao frio, dor e danificação estética. Clinicamente, ela resulta em uma superfície dentária lisa e brilhante quando acomete somente esmalte (aspecto vítreo do esmalte), na oclusal dos posteriores os desgastes pontuais em ponta de cúspides são chamados de "cupping", pode apresentar perda de esmalte com exposição da dentina amarelada por transparência (Figura 4) e em casos mais graves podemos observar o rósea identificando assim proximidade com a polpa. 
Figura 4 - Erosão dentária visão palatina.

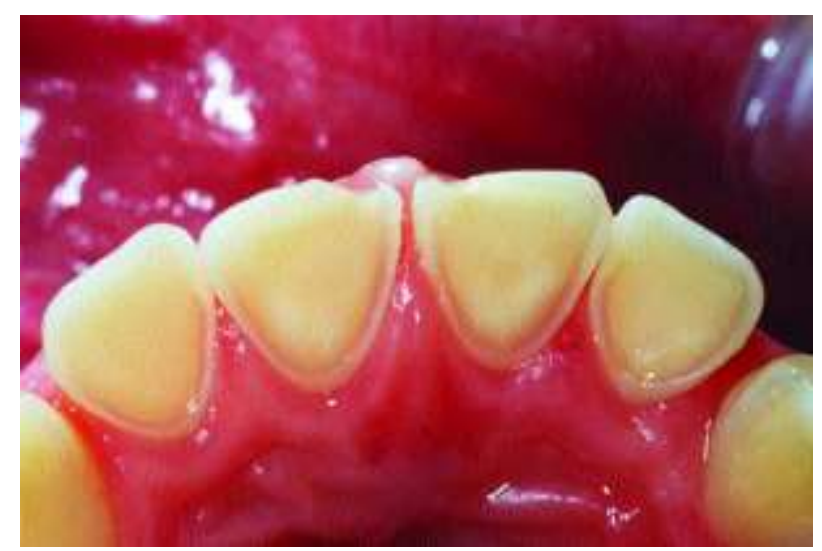

Fonte: MANGUEIRA et al., 2009.

\section{Xerostomia}

A xerostomia é um ressecamento temporário da cavidade bucal que na gravidez pode estar associado às alterações hormonais características do período (SBP, 2020, p. 8). Nesse caso é recomendado consumir água de forma frequente e fazer utilização de goma de mascar sem sacarose e contendo xilitol para aliviar o ressecamento. Uma segunda alternativa seria o uso de saliva artificial (ŁYSIK, et al., 2019), que é um líquido que reproduz a composição da saliva natural, possui propriedades lubrificantes fundamentais na proteção dos tecidos e no bom funcionamento do aparelho da fala, assim como na ingestão de alimentos.

\section{Granuloma gravídico}

O tumor gravídico, também conhecido como granuloma gravídico, é uma lesão benigna não neoplásica, reacional e multifatorial, sendo resultante de traumas ou irritações locais na mucosa (KRÜGER et. al., 2013). Ele apresenta crescimento rápido e costuma ocorrer entre o primeiro e terceiro trimestre (OLIVEIRA et al., 2014).

A remoção cirúrgica desse tumor pode ser necessária, sendo indicada em casos de interferência na mastigação ou no desempenho da higiene bucal e em situações de ulcerações (SBP, 2020).

Figura 5 - Aspecto clínico do granuloma gravídico recoberto por membrana necrótica.

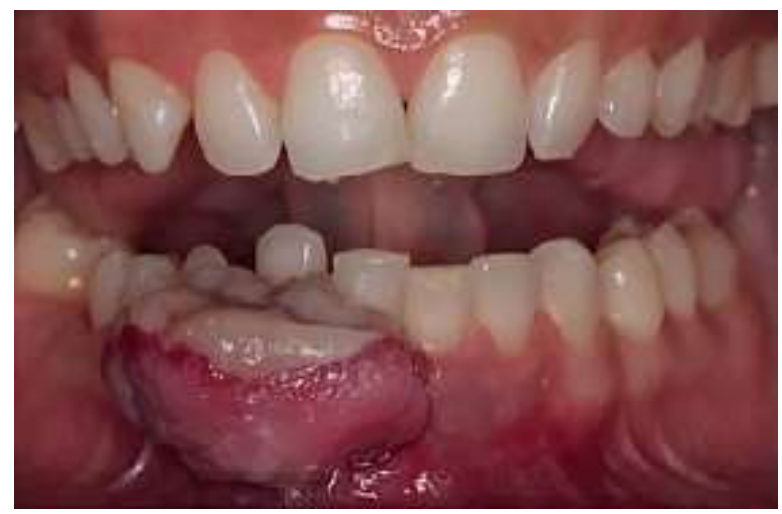

Fonte: $\underline{\text { http://revodonto.bvsalud.org/scielo.php?script=sci_arttext\&pid=S1677-38882013000400011. }}$. 


\section{$O$ atendimento odontológico durante a gravidez}

Todo tratamento odontológico essencial pode ser feito durante a gravidez, incluindo exodontias não complicadas, tratamento periodontal básico, restaurações dentárias, tratamento endodôntico e colocação de próteses, entre outros. Porém, por uma questão de bom senso, tratamentos mais extensos e cirurgias mais invasivas devem ser programados para o período pósparto. As consultas devem ser curtas, preferencialmente para a segunda metade do período da manhã, quando os episódios de enjoo são menos comuns em decorrência dos níveis do hormônio estrogênio e Human Chorionic Gonadotropin (HCG) no soro materno (ANDRADE, 2014). A posição ideal da gestante na cadeira odontológica deve ser de decúbito lateral para esquerda em um ângulo de aproximadamente $15^{\circ}$, o CD deve se atentar e levantar ligeiramente o encosto e solicitar que a paciente se vire sobre o braço esquerdo, assim evitando que a veia cava seja comprimida (UNA-SUS/UFMA, 2018).

\section{Trimestres gestacionais e o atendimento odontológico}

Cada trimestre gestacional apresenta características e cuidados dissemelhantes (Quadro 1), logo, a gestante deve ser observada, sendo importante ressaltar que urgências devem ser atendidas observando os cuidados indicados para cada período, sendo o segundo trimestre o mais indicado para o tratamento odontológico (SIQUEIRA; et al., 2020).

Quadro 1 - Trimestres gestacionais e o atendimento odontológico.

\begin{tabular}{|c|c|c|}
\hline Período & Características & Cuidados \\
\hline $\begin{array}{l}1^{\circ} \\
\text { Trimestre } \\
\text { Gestacional }\end{array}$ & $\begin{array}{l}\text { Período de desenvolvimento do feto (suscetível à } \\
\text { influência teratogênica e ao aborto). }\end{array}$ & $\begin{array}{l}\text { Postergar as intervenções odontológicas mais invasivas } \\
\text { para o segundo trimestre. }\end{array}$ \\
\hline $\begin{array}{c}2^{\circ} \\
\text { Trimestre } \\
\text { Gestacional }\end{array}$ & $\begin{array}{l}\text { É considerado o período mais indicado para } \\
\text { intervenções odontológicas; o feto se encontra com a } \\
\text { organogênese completa, logo, sendo o momento } \\
\text { adequado para a realização de intervenções. }\end{array}$ & $\begin{array}{l}\text { Podem-se realizar procedimentos odontológicos, desde } \\
\text { que se levem em conta anamnese, exames } \\
\text { complementares e avaliação de sinais vitais. }\end{array}$ \\
\hline $\begin{array}{c}3^{\circ} \\
\text { Trimestre } \\
\text { Gestacional }\end{array}$ & $\begin{array}{l}\text { Neste trimestre, há risco de síncope e hipertensão } \\
\text { arterial elevada devido à posição fetal, sendo ideal a } \\
\text { realização de procedimentos simples levando em conta } \\
\text { também o risco de estresse e bacteremia. }\end{array}$ & $\begin{array}{l}\text { Em casos de cirurgias invasivas, programar para o pós- } \\
\text { parto. Diante das urgências odontológicas (pulpites, } \\
\text { abscessos, etc.), o tratamento não pode ser adiado. }\end{array}$ \\
\hline
\end{tabular}

Fonte: Andrade (2014).

\section{Condutas farmacológicas}

Durante o PG é comum que se evite a prescrição medicamentosa, pois atualmente sabe-se que os fármacos podem atravessar a placenta e atingir a corrente sanguínea do feto. Antes da prescrição de um medicamento o profissional deve se atentar e avaliar se ele é seguro de acordo com o trimestre em que a gestante se encontra (EBRAHIM et al., 2014).

Analgésicos: dipirona e paracetamol podem ser utilizados na posologia correta. O emprego do ácido acetilsalicílico (AAS) deve ser feito com cuidado, já que apresenta tendência de causar hemorragias (VASCONCELOS et al., 2012).

Anti-inflamatórios: devem ser evitados, sobretudo no último trimestre de gestação; quando houver necessidade do uso, empregar dexametasona ou betametasona em dose única, levando em conta evidências de que corticosteroides não apresentam riscos teratogênicos (ANDRADE, 2014).

Corticosteroides: dexametasona e betametasona podem ser utilizados em caso de extrema necessidade, desde que em dose única de $4 \mathrm{mg}$ (ANDRADE, 2014).

Antibióticos: são considerados seguros para uso na gestação e lactação penicilinas (amoxicilina e ampicilina), cefalosporina, eritromicina do grupo estearato e macrolídeos (LONDRINA, 2017). Tetraciclinas são contraindicadas, pois esses antibióticos atravessam a membrana placentária, podendo ocasionar malformações no esmalte e descoloração dentária. Quanto 
ao metronidazol, pode passar para o leite materno; sendo assim, pode ser utilizado, porém em doses pequenas (500 mg/dia e por no máximo três dias) (ANDRADE, 2014).

Anestésicos: as soluções anestésicas devem conter um agente vasoconstritor com adrenalina ou noradrenalina, evitando que contenham como vasoconstritor a felipressina, que pode estimular contrações uterinas. O mais indicado para esse período é a lidocaína 2\% com adrenalina 1:100000 (LONDRINA, 2017).

\section{Exames radiográficos}

Se houver necessidade desses exames em gestantes, o profissional deve se atentar à radioproteção da paciente com EPIs plumbíferos: avental de chumbo para tórax, abdome e tireoide e ter preferência por técnicas de exposição baixas, evitando erros na tomada da radiografia e no processamento do filme, assim como repetições desnecessárias (ANDRADE, 2014,). Embora seja relatado que o bebê é sensível à radiação ionizante, os feixes de raios X na odontologia são limitados à região de cabeça e pescoço, sendo assim, a exposição fetal é de somente 1microgray ( $\mu \mathrm{Gy}$ ) quando feito um exame periapical completo, sendo considerada uma exposição mínima quando comparada com as recebidas por fontes naturais. Mesmo assim não se pode desconsiderar os efeitos da radiação secundaria e radiólise da água. Portanto, como a qualquer paciente esse exame pode ser realizado em caso de diagnósticos, devendo isso acontecer levando-se em conta toda a proteção necessária e ideal, sendo ela o usa do avental de chumbo protegendo toda a área abdominal (PHAROAH and WHITE, 2015).

\section{Discussão}

Atualmente o conhecimento científico demonstra que, apesar de estar claro na literatura que as doenças bucais podem influenciar de forma negativa o curso da gestação e causar danos à mãe e ao bebê, principalmente por conta das alterações apresentadas no PG, a insegurança das pacientes gestantes ao acompanhamento odontológico é uma realidade. Muitos mitos, crenças e inverdades deixam as gestantes inseguras quanto ao atendimento odontológico e essas pacientes têm receio do tratamento (OLIVEIRA et al., 2014), tendo em mente que o tratamento odontológico pode causar anormalidades congênitas, aborto e ou provocar danos ao bebê. O grande problema é que muitos CD também compartilham dessa ideia e acabam não se sentindo preparados para o atendimento clínico dessas pacientes. Mesmo sendo essencial a manutenção da saúde oral nesse período. (EBRAHIM et al., 2014)

Muitos profissionais sugerem que as visitas ao CD sejam adiadas para o pós-parto. Tendo como consequência o agravamento de simples problemas dentários que poderiam ser facilmente solucionados. Quando na verdade é a falta desses cuidados que podem gerar tais preocupações (OLIVEIRA et al., 2014). Portanto a conservação da saúde bucal durante o PG é de responsabilidade do $\mathrm{CD}$, que deve estar devidamente preparado para atendimentos preventivos e tratamentos necessários, além de informar sobre as patologias bucais e cuidados necessários com a chegada do bebê. Com isso as doenças bucais geradas pela falta de cuidado e falta de visitas ao CD (SBP, 2020) podem ser evitadas.

Um fator importante do PG é a mudança no estilo de vida, que leva a gestante á deixar de lado alguns cuidados diários. Como por exemplo a escovação adequada e o uso diário do fio dental, causando o agravo de doenças bucais, como a gengivite. Com o aumento excessivo dos hormônios nesse período capazes de agravar reações inflamatórias no tecido gengival (KONZEN, et. al 2019), e a falta de conhecimento sobre higienização (ZEMOLIN, et.al 2017), a gengivite apresenta-se de forma exacerbada com sangramentos, podendo ser considerada a doença bacteriana mais comum durante a gestação, e há um possível desenvolvimento da doença para uma periodontite. Caso haja evolução das desordens bucais, como por exemplo o desenvolvimento da gengivite para uma periodontite, existem trabalhos contraditórios na literatura sobre esse assunto. Apesar de alguns autores afirmarem que inflamações e infecções severas podem acarretar o nascimento prematuro (MAMEDE, 2018). 
Outros estudos não obtiveram os mesmos resultados para afirmar a relação entre a doença periodontal e o parto prematuro (SILVA et al., 2018). Mesmo não havendo esse consenso na literatura, é de responsabilidade do CD orientar em relação as consequências dos agravos bucais, e tratar as desordens bucais como a periodontia no PG.

As alterações hormonais também causam alterações na quantidade e qualidade salivar, levando assim a gestante estar propensa ao desenvolvimento de xerostomia (SBP, 2020). Com a diminuição da quantidade de saliva, temos também a diminuição da capacidade tampão da saliva na prevenção de lesões de cárie, também é de responsabilidade do CD, fazer uma boa anamnese das gestantes e observar aspectos clínicos que possam estar associados a xerostomia. E caso necessário estimular o uso de chicletes sem açúcar e até mesmo a recomendação de uso de saliva artificial. Junto com as alterações hormonais nesse período há ocorrência de vômitos, que acometem 70-85\% das gestantes. (EBRAHIM et al., 2014), esses vômitos podem modificar a flora oral, deixando os dentes mais predispostos ao surgimento da lesão de cárie (SBP, 2020), assim como a erosão dentária. Os cuidados são bem simples e baseados em orientações de prevenção e profilaxia profissional mensal ou trimestral, aplicações de flúor caso necessário (LONDRINA, 2017), dependendo da necessidade de cada paciente (OLIVEIRA et al., 2014). O granuloma gravídico apesar de raro, pode ser considerado um problema de saúde bucal no PG (OLIVEIRA et al., 2014), na sua maioria das vezes está associado com a presença de placa e cálculo, podendo ser evitado com tratamentos de remoção desses fatores. Porém em alguns casos, a remoção cirúrgica desse tumor pode ser necessária (SBP, 2020, p. 8), o que não é um problema para o CD bem orientado, pois com corretas medicações e correta dosagem de anestésico, uma cirurgia simples pode ser executada sem maiores riscos, lembrando que o segundo trimestre o mais indicado para o tratamento odontológico (SIQUEIRA; et. al, 2020). As consultas devem ser curtas, preferencialmente na segunda metade do período da manhã, quando os episódios de enjoo são menos comuns em decorrência dos níveis do hormônio estrogênio e HCG (ANDRADE, 2014). O segundo trimestre também é o mais indicado para o tratamento odontológico (SIQUEIRA; COSTA \& ALMEIDA, 2020), mas não há na literatura contraindicação de atendimento nos outros períodos. Com isso atendimentos de urgências devem acontecer em qualquer período sendo levado em conta os cuidados indicados em cada período da gestação. (DIAS, 2014; SIQUEIRA; COSTA \& ALMEIDA, 2020).

Apesar de no PG ser comum que se evite a prescrição medicamentosa, é de responsabilidade do CD avaliar a necessidade da prescrição de um medicamento o de acordo com o trimestre em que a gestante se encontra (EBRAHIM et al., 2014). Porém muitos medicamentos podem ser usados sem nenhum risco como, por exemplo, corticosteroides (ANDRADE, 2014, p. 170) e antibióticos. No caso da necessidade de procedimentos mais invasivos, como, por exemplo, pequenas cirurgias e tratamentos endodônticos, o anestésico de escolha para o PG é a lidocaína 2\% com adrenalina 1:100000 (LONDRINA, 2017). Demonstrando assim que pacientes gestantes podem sim passar por procedimentos mais invasivos quando necessário, não havendo necessidade de adiar os procedimentos para o período pós-parto.

As tomadas radiográficas caso necessário não são contraindicadas para o PG (EBRAHIM et al., 2014). Somente se atentar ao fato de que alguns cuidados devem ser tomados como: uso correto do protetor de chumbo protegendo toda a área abdominal (PHAROAH and WHITE, 2015), evitar repetições desnecessárias (ANDRADE, 2014,). E apesar de haver uma necessidade maior de cuidados com a paciente gestante, esses cuidados são de extrema importância em todos os pacientes, estando em PG ou não, levando assim para o CD segurança em executar tais procedimentos em qualquer paciente.

É dever do CD ter um olhar integral e ampliado, a fim de realizar a promoção da saúde de sua paciente gestante durante o pré-natal, abordando questões específicas da saúde bucal. (SIQUEIRA; COSTA \& ALMEIDA, 2020). Sempre que possível, fazer o contato com o obstetra responsável pelo acompanhamento da gestante, visando troca de informações valiosas, realizando tratamento odontológico avaliando risco/benefício. (DIAS, 2014). A gestante deve ser estimulada por médicos e CD a realizar o acompanhamento odontológico, e não esperar o fim da gestação para procurar atendimento. (DIAS, 2014). As alterações no PG acontecem na cavidade oral quando aliadas a falta de conhecimento e técnicas de higienização que geram condições 
predisponentes às doenças bucais. (ZEMOLIN, et.al 2017). A higiene oral, portanto, deve ser enfatizada durante a gestação (EBRAHIM et al., 2014), de modo a prevenir os riscos à gestante e ao bebê, garantindo melhor saúde sistêmica e qualidade de vida. Diante desse estudo podemos observar que com procedimentos simples e orientações de prevenção, tratamentos mais invasivos podem ser evitados, e os tratamentos necessários devem ser realizados nas gestantes evitando riscos de saúde para a mão e para o feto, determinando assim a importância de se estimular o PO por parte dos CD nas pacientes gestantes.

\section{Considerações Finais}

$\mathrm{O}$ fato de pacientes gestantes e principalmente $\mathrm{CD}$ acreditarem nas crenças e mitos diante do tratamento odontológico durante a gravidez dificultam o cuidado da saúde bucal dessas pacientes. Quando na verdade o profissional da saúde deve ter consciência da necessidade de realizar a promoção da saúde de sua paciente gestante, orientando e prevenindo o desenvolvimento de agravos bucais. Principalmente pelo fato de que os conhecimentos científicos atuais demonstrarem que o pré-natal odontológico deve ser realizado pelos cirurgiões dentistas, assim como procedimentos invasivos ou não durante esse período, pois os possíveis fatores de risco podem determinar doenças mais graves durante o período gestacional.

Para que o atendimento odontológico a gestante possa virar ações e ampliar o acesso das gestantes ao tratamento odontológico, novos estudos que auxiliem no planejamento de políticas eficazes de saúde bucal para gestantes poderiam ser conduzidos. Incluindo políticas públicas que incentivaria os $\mathrm{CD}$ a promover a saúde bucal durante a gestação. Esses estudos ajudariam a desmistificar mitos e crenças, além de ser necessário investir na educação permanente dos profissionais de saúde envolvidos com o pré-natal odontológico, para que possam garantir o atendimento adequado às gestantes.

\section{Referências}

ANDRADE, Eduardo Dias de. Terapêutica medicamentosa em odontologia. Artes Médicas Editora, 2014.

CARMO, Weder Dias. A importância do pré-natal odontológico. Revista Cathedral, v. 2, n. 3, p. 145-156, 2020.

EBRAHIM, Zahra Fernandes et al. Tratamento odontológico em gestantes dental treatment during pregnancy. Science, v. 5, n. 1, p. 32-44, 2014.

Global Child Dental Fund, Guia de Saúde Oral Materno Infantil. Sociedade Brasileira de Pediatria. SBP, 2020,30 páginas.

GUIMARÃES, K. A.; SOUSA, G. A.; COSTA, M. D. M. de A.; ANDRADE, C. M. de O.; \& DIETRICH, L. Gestação e Saúde Bucal: Importância do pré-natal odontológico. Research, Society and Development, v. 10, n. 1, p. e56810112234, 2021.

KONZEN JÚNIOR, D., MARMITT, P. L., \& CESAR, A. J. Não realização de consulta odontológica entre gestantes no extremo sul do Brasil: um estudo de base populacional. Ciência e Saúde coletiva, Rio de Janeiro, v. 24, n. 10, p.3869-3896, 2019.

KRÜGER, Marta Silveira da Mota et al. Granuloma gravídico-relato de caso. Odontologia Clínico-Científica (Online), v. 12, n. 4, p. $293-295$, 2013.

ŁYSIK, Dawid et al. Artificial saliva: challenges and future perspectives for the treatment of xerostomia. International journal of molecular sciences, v. 20, n. 13, p. 3199, 2019.

MANGUEIRA, Dayane Franco Barros et al. Cárie e erosão dentária: uma breve revisão. Odontologia Clínico-Científica (Online), v. 10, n. 2, p. 121-124, 2011.

Município de Londrina - Paraná, Brasil. Manual do Cuidado no Pré-Natal e Puerpério na Atenção Primária em Saúde. Londrina - PR, 2017,420 páginas.

OLIVEIRA, Eliana Cristina de et al. Atendimento odontológico a gestantes: a importância do conhecimento da saúde bucal. Revista de Iniciação Científica da Universidade Vale do Rio Verde, v. 4, n. 1, 2014.

SILVA, C. C. da; MARONEZE, M. C.; ZAMBERLAN, C.; \& SANTOS, B. Z. dos. Capacitação sobre o pré-natal odontológico para profissionais da equipe de saúde: relato de experiência. Research, Society and Development, v. 9, n. 8, p. e204984481, 2020.

SILVA, Emmeenny Rickelly. Cárie dentária como uma disbiose da cavidade bucal: consequências nas estratégias de prevenção e controle da doença. 2020.

SILVA, M. E. C.; AMADOR, A. M. R.; \& TOLENTINO JÚNIOR, D. S. A importância da odontologia para as gestantes: Uma breve revisão. Research, Society and Development, v. 10, n. 6, p. e0810615515, 2021.

SILVA, Patrícia Nienkotter Sad et al. Associação entre doença periodontal, parto prematuro e baixo peso ao nascer. Revista Cubana de Estomatología, v. 55, n. 1, p. 26-33, 2018 . 
SIQUEIRA, Caroline Maia; DE CARVALHO COSTA, Paulini Malfei; \& DE ALMEIDA JUNIOR, Paulo André. Atenção em saúde bucal da gestante: sua importância, medos e mitos relacionadOS. Ciência Atual-Revista Científica Multidisciplinar do Centro Universitário São José, v. 16, n. 2, 2020.

THAKUR, Vishal et al. Pregnancy \& Oral Health and Dental Management in Pregnant Patient. Journal of Current Medical Research and Opinion, v. 3, n. 11, p. $724-731,2020$.

Universidade Federal do Maranhão. UNA-SUS/UFMA. Assistência à saúde bucal da gestante e da puérpera. São Luís, 2018.

VASCONCELOS, Rodrigo Gadelha et al. Atendimento odontológico a pacientes gestantes: como proceder com segurança. Revista brasileira de odontologia, v. 69 , n. 1 , p. 120,2012

WHITE, Stuart C.; PHAROAH, Michael J. Radiologia oral-E-Book: Princípios e interpretação. Elsevier Health Sciences, 2015.

ZEMOLIN, Alexia Belchor et al. Gestantes: da saúde bucal a saúde geral. Rev Saúde Integr, v. 10, n. 20, p. 76-80, 2017. 